\title{
Emotional Intelligence: Conceptualisation and Prediction of Consumer Decision Making
}

\footnotetext{
Osama Akram Khan', Muhammad Asim², Salman Manzoor ${ }^{3}$

${ }^{1}$ Karachi University Business School (KUBS), University of Karachi, Karachi

${ }^{2}$ Associate Professor, Karachi University Business School (KUBS), University of Karachi, Karachi

${ }^{3}$ Karachi University Business School (KUBS), University of Karachi, Karachi

A B S T R A C T

This study aimed to explore emotional intelligence and rationality as the factors to be affecting consumer decision-making. The reason behind the part predicting the consumer decision making is very crucial for the organizations. The consumer's decision-making towards a product is based upon their emotional intelligence, instead of the past studies and researches done in the required as well as the related fields. Using a quantitative research design, this study collected data from the individuals who were the decision-makers. An adopted research instrument with a 5-point Likert scale and included statements about the individuals' behavior, perception, and decisionmaking (Emotionality and rationality) was used. The findings of the study demonstrate that a consumer's decision-making is primarily related to the understanding of the emotional intelligence of a consumer (Seller to be emotionally intelligent) and the understanding of the rationale of a consumer (Seller to be rational). The results in the reviewed literature were found to be similar to the findings of the present study.
}

Keywords: Emotional intelligence, rational of consumer, decision-making

\section{INTRODUCTION}

In the past couple of years, especially in the current era that we are living in, we as a population and as a system has seen great shifts in the trends of the workings of the world, be it related to the betterment of living standards or for the betterment of businesses especially the marketing and sales sector. The evolving mentality and the change in the thinking capacity of humans have played a vital role since the very beginning. With the current annual growth standing at around $2 \%$ per annum (Pakistan population, 2020), as well as being in such a scenario of a pandemic, it has forced the people to shift towards alternate routes/techniques to keep the economic cycle stable (Ozili \& Arun, 2020). During all this, the challenge of understanding the needs of the 
consumer even without them saying it has peaked a lot, and because of this, many have shifted towards a better understanding of Emotional Intelligence to get ahead in the game. (Bhalerao \& Sharma, 2018)

Our research focuses on the conceptualization of Emotional Intelligence, and to try to predict the consumer's decision-making towards a product based upon their emotional intelligence, instead of the past studies and researches are done in the required as well as the related fields. To be specific, our area of focus also included consumer emotional intelligence. (HEJASE, SKAFF, SKAFF, \& HEJASE, 2018). Emotional intelligence is defined as the ability of an individual to perceive the emotions, then work their way through to think, process, and understand the emotions and emotional knowledge and regulate emotions for promotion of emotional and intellectual knowledge(Mayer \& Salvoy, 1997). The set of abilities, as per the MSCIET $^{\mathrm{TM}}$, measures the perception, usage, understanding, and managing of emotions to achieve goals and make life decisions daily or when in a situation.

According to Zahid A. et. al., 2019, the conceptualization, measurement, and measurement of Emotional Intelligence differs from culture to culture hence to get ahead in the particular/said field of scope, one must consider such things. The reason behind the part predicting the consumer decision making is very crucial for the organizations. Understanding the buying behavior or the decision-making of a consumer is like figuring out the correct key for the lock. By doing this not only it will become easier for the organizations to produce things accordingly, but it will also help them get an advantage over the competitors when it will come to terms with consumer preference, because somewhere deep down, all of us want to be treated like royalty. (Jones, 2018)

\section{LITERATURE REVIEW}

EI has proved to be an integral part of not just the training and development of the individuals, but it has also been launched as a separate course in Yale, and similarly, following fashion/pursuit, many of the organizations such as Google have fallen into the footsteps and have started the training and development of the graduating students as well as the employees. (Mattingly \& Kraieger, 2018). The bigger question that arises is that can this trait of a human being be trained or is it just to be observed and then learn from 
the outcomes of the behavior of a person who is going to be of our interest. Is the understanding going to be enough to predict the consumer's behavior or is it for us to train them in a certain way that they are attracted to our products and create a consumer pull? According to Mattingly \& Kraiger, 2018, emotional intelligence is crucial in organizational development and the result can be seen in the well-doing of the organization as well as the boosted sales numbers.

As per Mubashar H. et. al., 2018, Impulsive buying which is an unplanned decision to buy a product or service made just before purchase, is found to be affected by both; gender and emotional intelligence, hence proving that the higher the emotional intelligence, the lower will be the impulsive buying habit and vice versa. In the study of Awan \& Abbas (2015), it was analyzed that males made more impulsive buying than females. Thus, these factors are of great value to marketing managers. Edwardson, M. (1998) observed that consumer emotions are critical for any business and they can target these customer dimensions to boost their market share and sales. Hence strengthening our point and reason behind establishing such a study. Dispositional Mindfulness can be defined as a personal attribute that allows an individual to be well aware of the present moment event during ordinary tasks. Several studies have been conducted to find the relationship between Mindfulness and Impulsive buying and the results show that individuals with greater mindfulness have higher self-regulation and reduced impulsive reactions and thus a reduced irresistible buying. Also, Mindfulness has a positive impact on Emotional intelligence as mindful individuals can make proper use of their emotions in making a decision or handling a particular situation. (Park \& Dhandra, 2016)

A consumer is an individual who pays to consume the goods or the services provided by the seller. Consumer behavior is the study of all the activities linked with the purchase and use of goods and services and the factors influencing buying behavior including the consumer's attitudes, preferences, and emotions. It also aids the companies in identifying opportunities that are currently not met (Misron \& Hee, 2021).

A change in consumer behavior is highly noticed in times of crisis as the current socioeconomic situations greatly affect consumers' buying patterns. In 2009, Flatters and Willmott conducted a study in which it was concluded that consumers prefer to buy 
simpler offerings with great value. Even this affects rich people who encouraged the concept of recycling and make efficient use of their supplies.sc(Mehta et al., 2020). According to Kerry D. Carson et. al. 2016, a 30 item measure when used, was able to determine the employees' emotional intelligence perception, although it had some shortcomings, it was useful. Keeping in mind that if those areas of shortcomings can be avoided, and either research is conducted over those neglected areas or they are somehow how managed, then it will be of great importance if the same concept is applied on the consumer level. Once again, raising the point that it will be easy for the organizations to predict the decision-making of the consumer.

According to Hemangi Bhalerao and Kiran Sharma (2018), in their study regarding emotional intelligence and repeated buying behavior, they suggested that emotional component is very crucial when it comes to customer satisfaction related to a specific product/brand. The switching towards a competitor is due to a lack of affective connotation. Hence making it an important part to try and fully understand the emotions of a consumer, not just to provide satisfaction but also to keep them retained to our product. Moreover, they suggested that marketers can benefit from this emotional data by analyzing and understanding it and as a result derive different marketing strategies. Furthermore, an individual while making a decision tries to maintain a balance between emotions and rationality, out of which mostly, emotionality dominates (Stankevich, 2017). But emotional intelligence itself can prove to be viable since it incorporates all the four domains as discussed and described by Mayer et. al. (2007). It is very important to note that at times, after purchasing a product, an individual may feel guilty, because of the fact he/she was compelled to buy it because of the impulse buying nature. But if we get to the level of understanding their emotional intelligence, then it will be much easier to predict their decision-making while purchasing. It has been observed in many places that there is some sort of connection that lies between the understanding of the consumer's behavior and their emotional intelligence, which in turn will be able to help the marketers, business owners, organizations, etc to benefit from this by predicting their steps or buying behavior. (O'Connor, Hill, Kaya, \& Martin, 2019)

This study explores the impact of online promotions among the buyer and their 
effect upon the buying decision of the consumer. Findings showed that there is a positive response and relationship when it came to such promotions online and triggered the impulse buying nature of the consumer (Rajput \& Talan, 2017). Due to the fast adoption of social media content among the customers and organizations, this context was to reveal the impact of online promotion behavior and find the interaction of buying behavior as a consumer. Perhaps, the research model was comprised of the combination of perceived transaction value, acquisition value, reviews information, emotional intelligence, buying tendency, promotional effect, theory of selective attention, and stimulus-organism-response framework. (Zafar et al., 2020)

Another study conducted showed that impulse buying increases with age, money and has a higher rate in females. (Nair, 2019). In another study conducted, showed that gender has a definite impact when it comes to the fact of impulse buying and hence has a great scope in the future. (Zia et al., 2018). In another study where dispositional mindfulness and impulsive buying tendency were studied, the results showed a negative effect between the two. Although, the aspects of emotional intelligence (use of emotions, self-emotion appraisal, and regulation of emotion), fully mediated the mindfulness and IBT and as a result, the understanding of all this will help in understanding the mechanism of how mindfulness enhances EI, which further influences impulsive buying. (Park \& Dhandra, 2016). In a study conducted to check the relationship between EI and consumers' choice of food, the results came out as, that consumers with low EI are less likely to choose food with nutritional claims as compared to those with a higher EI score. (Lopez-Galan et al., 2017). Another study conducted showed that online training regarding the understanding of emotions was useful and as a result was productive since it improved the recognition of emotion and facial expression in the tourism employees.(Koc \& Boz, 2019). Another study provides data and analysis which interpreted as, that impulsive buying relies on the age, gender, and education of the consumer, while the consumer emotional intelligence was kept as a moderator (Nadeem et al., 2017)

In another study, having emotional intelligence as a mediator while checking the effects of depression and the fear of missing out, it was concluded that a negative 
relationship between EI and depression as well as EI and the fear of missing out (FoMo) existed, although FoMo has a depressing effect on the individual through EI (Kartol \& Gundogan, 2020). Thus, research finds that consumer emotional intelligence (CEI) is an important aspect to explore why consumers act differently upon the consumer positive brand relationships and some of the consumers react negatively. Hence, the result of the study depict that (1) whenever come across transgressions in relationship with the brand then consumers low in CEI; (2) the destructive responses is greater on the effect of CEI whenever the transgression effects of consumer self-interest as compared to society interest; and (3) low CEI bring the negative attributes towards the company and more respond to the destructively as contrast high CEI consumers. In another study, the relationship between consumer EI and transgression was observed and the results indicated that consumers. (Ahn et al., 2015). While another study provides evidence that culture is a factor that is going to impact the Trait EI, and the results indicate that males score higher on self-control while the females scored higher on emotionality and the recommendation of including EI in the academic process of the universities should be followed (Ahmed et al., 2019).

\section{Theoretical Framework}

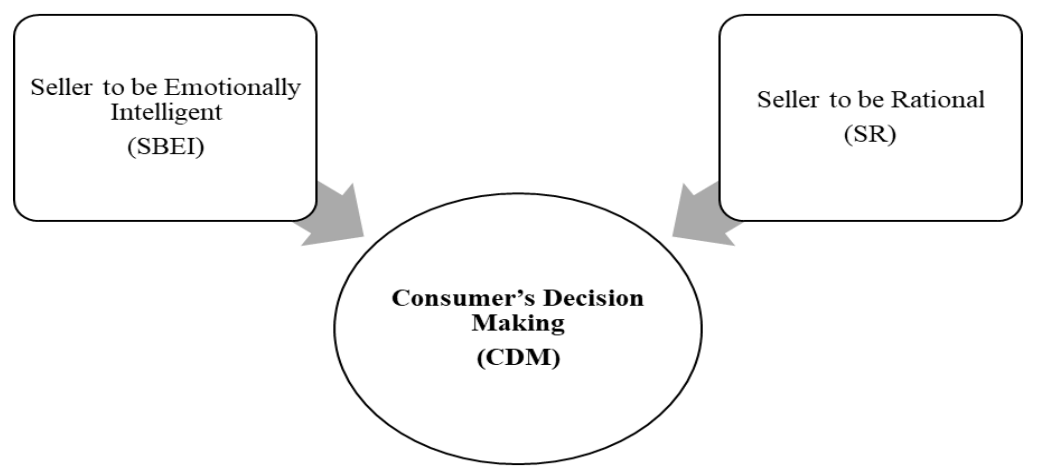

The independent variable is the seller's understanding of the consumer's emotional intelligence, and it has been broken into 2 factors.

The seller is emotionally intelligent so that they can understand the consumer and as a result intervene in their decisions and influence them. 
The seller is rational and not being dependent on the emotional side and hence taking decisions that will influence the consumer's decisions.

While the dependent variable is the consumer's decision predicting because that is what our main focus is and hence is been divided into 2 factors as well:

The emotionality of the consumer. As it is one of the major factors which influences a prompt decision and impulse buying.

The rationality, or in other words the whole process of perceiving, understanding, and processing the emotions for the decision making, can also be termed as the EI of the consumer.

The basic idea behind this study is to understand the emotional intelligence of the consumer as well their behaviors and then by trying to understand it, predict their decision making. This can be helpful to the organizations because by doing so not only can the specific product be designed, but also the consumer can be engaged in multiple ways hence increasing satisfaction and loyalty. (SERGIENKO, KHLEVNAYA, \& OSIPENKO, 2020). Another way to look at it is that we can cut off the consumer at the part where they start processing the emotions and as a result influence their decisions. One thing to keep in mind is that no matter what the strategy is followed, the consumer must be able to understand the EI of the consumer. If the organizations, who are producing goods in such a manner that they want to keep the consumer engaged with themselves while enjoying the maximum share of the market and reap maximum benefits from it, their need to understand the emotional intelligence of a consumer is really important so that they can predict the decision making of the consumer and hence provide them with such products and services which will keep them satisfied and hence occupied to a specific brand(Vredeveld, 2018). The understanding of the emotional intelligence of the consumer does not affect whatsoever the prediction of decision making of a consumer because the emotions vary from one individual to other and it is not feasible to do so. Hence the relationship does not exist.

As per the variables, the following hypotheses are generated:

$\mathbf{H}_{1}$ : the understanding of the emotional intelligence of a consumer (Seller to $\mathrm{Be}$ Emotionally intelligent) has a significant impact on the prediction of the 
consumer's decision making

$\mathbf{H}_{2}$ : the understanding of the rationale of a consumer (Seller to Be rational) has a significant impact on the prediction of the consumer's decision making

\section{METHODOLOGY}

Two questionnaires, consisting of 15 questions each were developed after adapting and then changing the questions slightly as per the need. The questions were adapted from the CIES (Consumer Emotional Intelligence Scale) which consists of an 18item assessment, MSCEIT ${ }^{\mathrm{TM}}$ (Mayer-Salvoy-Carusso Emotional Intelligence Test) which consists of 141 questions and covers the 4 domains of emotional intelligence, and TEIQue (Trait Emotional Intelligence Questionnaire) which consists of 153 items and covers even more vast domain of the emotional intelligence. The questions consisted of a 5-point Likert scale and included statements about the individuals' behavior, perception, and decision making (Emotionality and rationality). The questions of the second questionnaire were of a similar fashion in terms of the 5-point Likert scale, but the questions were directed more towards the perspective of a seller and how they interpret the behavior and decision making of a consumer (Emotionality and rationality). The 313 respondents for each tool were shortlisted. For the buyers, individuals who are the decision-makers were targeted and hence were divided over an age group of 20-60 years and the majority of the respondents were graduate level.

While for the sellers, a similar number of respondents were shortlisted in the age group of 20-60 years and the majority of the respondents were non-business graduates but were either business owners or had a role as a salesperson/marketer/business owner, etc. Reliability analysis is a measure for the properties as well as the composition in the scale items. Information regarding the relationship between individual items as well as the relationship between in-class and intra-class coefficients can be used to calculate this estimate. (Melchers \& Beck, 2018) The values for Cronbach alpha to be in an acceptable range need to be greater than 0.5 and less than 0.6 , but they are termed as poor. When the value is greater than 0.6 and less than 0.7 , then it is questionable and when the value is greater than 0.7, but less than 0.8 , then it is considered acceptable. (Glen, 2014)

Another thing to keep in mind is that we have assumed to be in a positive area. 
For example, we supposed that understanding the consumer behavior, will help us understand their decision making and hence we will be able to predict it, but at the same time, conceptualizing that it will be easier for the organizations to produce things, can also be a hassle as the consumer preference varies from one individual to other. The data has been collected majorly from the region of Karachi, Sindh. It can be noted easily that to get a more in-depth analysis and insight, data collection will have to be done on a larger scale if someone decides to work on a global level or a national level.

\section{RESULTS \& FINDINGS}

This chapter presents the analysis of the collected data from the participants. From this perspective, it will be distributed into three parts. The first part of the data analysis is associated with the descriptive analysis that describes the participants and their responses. The second part of it presents the internal consistency of the items used to collect data on the chosen constructs/variables. The last part of this chapter discusses the inferential analysis to justify the stated hypotheses.

\section{Descriptive Statistics of Participants}

Table 1 shows the demographic characteristics of the participating individuals in this study. From this perspective, it demonstrates that among the total number of participants $(\mathrm{n}=250) 111(44.4 \%)$ were female and $139(55.6 \%)$ were male. The significant number of participants was of the age group between 20 and 30. Most of the respondents had the educational level of intermediate.

\section{Descriptive Statistics of Responses}

Table 2 describes the received responses. In this way, the mean score of the variable SBEI was 4.09 having .602 as standard deviation and .363 as a variance. The variable SR was 4.04 having .611 as standard deviation and .374 as a variance. The variable CDM was 4.17 having .460 as standard deviation and .212 as a variance.

\begin{tabular}{|c|c|c|}
\hline \multicolumn{3}{|c|}{ Gender } \\
\hline & Frequency & Percent \\
\hline Female & 111 & 44.4 \\
\hline Male & 139 & 55.6 \\
\hline
\end{tabular}


Table 2: Descriptive Statistics of Responses

\begin{tabular}{|c|c|c|c|c|c|}
\hline \multirow{3}{*}{\multicolumn{3}{|c|}{ NICE Research Journal, Vol.14 No.2 (2021): Ap }} & \multirow{2}{*}{\multicolumn{2}{|c|}{ SBEI }} & \multirow{2}{*}{ SR CDM } \\
\hline & & & & & \\
\hline & & & Valid & 250 & 250 \\
\hline & & & Missing & 0 & 0 \\
\hline Total & 250 & 100.0 & Mean & 4.0712 & 4.10934 .0019 \\
\hline \multicolumn{3}{|c|}{ Age Group } & Std. Deviation & .60802 & .54601 .48369 \\
\hline $20-30$ & 188 & 75.2 & Variance & .370 & $.298 \quad .234$ \\
\hline $31-40$ & 43 & 17.2 & Skewness & -.980 & $-.543 \quad-.321$ \\
\hline $41-50$ & 13 & 5.2 & \multirow{3}{*}{$\begin{array}{c}\text { Std. Error of } \\
\text { Skewness }\end{array}$} & \multirow{2}{*}{.154} & \multirow[t]{2}{*}{.154} \\
\hline $51-60$ & 6 & 2.4 & & & \\
\hline Total & 250 & 100.0 & & & \\
\hline \multicolumn{3}{|c|}{ Educational Qualification } & Kurtosis & 2.321 & .131 \\
\hline Intermediate & 186 & 74.4 & \multirow{4}{*}{$\begin{array}{c}\text { Std. Error of } \\
\text { Kurtosis }\end{array}$} & \multirow[t]{2}{*}{.307} & \multirow[t]{2}{*}{.307} \\
\hline Graduation & 43 & 17.2 & & & \\
\hline Post-Graduation & 21 & 8.4 & & & \\
\hline Total & 250 & 100.0 & & & \\
\hline
\end{tabular}

\section{Reliability}

Table 3 shows the internal consistency between the items used under each variable. The internal consistency was measured via Cronbach Alpha test appliaed in SPSS. According to Taber (2018), "alpha values were described as excellent (0.93-0.94), strong (0.91-0.93), reliable (0.84-0.90), robust (0.81), fairly high (0.76-0.95), high (0.73-0.95), good (0.71-0.91), relatively high (0.70-0.77), slightly low (0.68), reasonable (0.67-0.87), adequate $(0.64-0.85)$, moderate $(0.61-0.65)$, satisfactory $(0.58-0.97)$, acceptable (0.45-0.98), sufficient (0.45-0.96), not satisfactory (0.4-0.55) and low (0.11)" (p. 1278).

\section{Table 3: Internal Consistency Test}

\begin{tabular}{cccc}
\hline \multicolumn{4}{c}{ Reliability Statistics } \\
\hline Constructs & Cronbach's Alpha & N of Items & Items Deleted \\
\hline SBEI & .7276 & 5 & -- \\
\hline SR & .747 & 6 & -- \\
\hline CDM & .632 & 5 & CDM3, CDM 5 \\
\hline
\end{tabular}

\section{Inferential Statistics}

To test the relationship between the used variables, the Pearson correlation test was run. The results of the Pearson correlation test are displayed in table 4 . 


\section{Table 4: Correlations}

\begin{tabular}{ccccc}
\hline & \multicolumn{5}{c}{ SBEI } & SR & CDM \\
\hline \multirow{3}{*}{ SBEI } & Pearson Correlation & 1 & & \\
\cline { 2 - 5 } & Sig. (2-tailed) & & & \\
\cline { 2 - 5 } & $\mathrm{N}$ & 250 & & \\
\hline \multirow{3}{*}{ SR } & Pearson Correlation & $.553^{* *}$ & 1 & \\
\cline { 2 - 5 } & Sig. (2-tailed) & .000 & & \\
\cline { 2 - 5 } & $\mathrm{N}$ & 250 & 250 & 250 \\
\hline \multirow{3}{*}{ CDM } & Pearson Correlation & $.687^{* *}$ & $.733^{* *}$ & \\
\cline { 2 - 5 } & Sig. (2-tailed) & .000 & .000 & \\
\cline { 2 - 5 } & $\mathrm{N}$ & 250 & 250 & \\
\hline
\end{tabular}

**. Correlation is significant at the 0.01 level (2-tailed).

To test the stated hypotheses, Inferential Statistics was used. From this perspective, the backward regression test was run using SPSS. Tables 5, 6, and 7 display the results of the backward regression test. Table 5 shows the overall impact of independent variables on the dependent variable $(\mathrm{R}=.807)$ which is $80.7 \%$. It means, with the change in the independent variables, the dependent variable changes up to 80.7 percent.

\begin{tabular}{|c|c|c|c|c|}
\hline \multicolumn{5}{|c|}{ Table 5: Model Summary } \\
\hline Model & $\mathbf{R}$ & $\begin{array}{c}\text { R } \\
\text { Square }\end{array}$ & $\begin{array}{l}\text { Adjusted } \\
\text { R Square }\end{array}$ & $\begin{array}{l}\text { Std. Error } \\
\text { of the } \\
\text { Estimate }\end{array}$ \\
\hline 1 & $.807 \mathrm{a}$ & .651 & .648 & .28693 \\
\hline
\end{tabular}

\begin{tabular}{|c|c|c|c|}
\hline \multicolumn{4}{|c|}{ Table 6: ANOVA } \\
\hline Model & $\begin{array}{c}\text { Sum of df } \\
\text { Squares }\end{array}$ & $\begin{array}{c}\text { Mean } \\
\text { Square }\end{array}$ & Sig. \\
\hline Regression & 37.920 & 18.960 & $230.295 .000 \mathrm{~b}$ \\
\hline 1 Residual & 20.335 & .082 & \\
\hline Total & 58.255 & & \\
\hline \multicolumn{4}{|c|}{ a. Dependent Variable: CDM } \\
\hline b. Predictor & (Constant), S & BEI & \\
\hline
\end{tabular}

The sig value (.000) in table 6 model 4 shows that the prescribed model is a good fit to test the regression.

\section{Table 7: Coefficients}

\begin{tabular}{|c|c|c|c|c|c|c|}
\hline \multirow[t]{2}{*}{ Model } & \multicolumn{2}{|c|}{$\begin{array}{l}\text { Unstandardized } \\
\text { Coefficients }\end{array}$} & $\begin{array}{l}\text { Standardized } \\
\text { Coefficients }\end{array}$ & \multirow[t]{2}{*}{ Sig. } & \multicolumn{2}{|c|}{$\begin{array}{l}\text { Collinearity } \\
\text { Statistics }\end{array}$} \\
\hline & B & Std. Error & Beta & & Tolerance & VIF \\
\hline (Constant) & .838 & .149 & & 5.635 .000 & & \\
\hline 1 SBEI & .323 & .036 & 406 & 8.992 .000 & 694 & 1.441 \\
\hline SR & .450 & .040 & 508 & 11.261 .000 & 694 & 1.441 \\
\hline
\end{tabular}

a. Dependent Variable: CDM

The sig values (.000 less than .05) in table 7 show that the independent variables have a statistically significant impact on the dependent variable. The positive B values 
show that the independent variables have a positive impact on the dependent variable.

\section{Summary of Hypotheses}

\begin{tabular}{clcc}
\hline No & \multicolumn{1}{c}{ Statement } & $\begin{array}{c}\text { Sig } \\
\text { Value }\end{array}$ & Status \\
\hline $\mathrm{H}_{1}$ & $\begin{array}{l}\text { The understanding of the emotional intelligence of a consumer } \\
\text { (Seller to be Emotionally intelligent) has a significant impact on the } \\
\text { prediction of the consumer's decision-making }\end{array}$ & .000 & Accepted \\
\hline $\mathrm{H}_{2}$ & $\begin{array}{l}\text { The understanding of the rationale of a consumer (Seller to be } \\
\text { rational) has a significant impact on the prediction of the } \\
\text { consumer's decision-making }\end{array}$ & .000 & Accepted \\
\hline
\end{tabular}

$\mathbf{H}_{1}$ : The understanding of the emotional intelligence of a consumer (Seller to be Emotionally intelligent) has a significant impact on the prediction of the consumer's decision-making

$\mathbf{H}_{2}$ : The understanding of the rationale of a consumer (Seller to be rational) has a significant impact on the prediction of the consumer's decision-making

\section{DISCUSSION}

Statistical studies have shown that a consumer's decision-making is primarily related to the understanding of the emotional intelligence of a consumer (Seller to be emotionally intelligent) and the understanding of the rationale of a consumer (Seller to be rational). The results in the reviewed literature are very much similar to the findings of the present study which show the same findings. For instance, the study conducted by Nadeem et al., (2017) found that impulsive buying relies on the age, gender, and education of the consumer, while the consumer's emotional intelligence was kept as a moderator. According to Hemangi Bhalerao and Kiran Sharma (2018), in their study regarding emotional intelligence and repeated buying behavior, they suggested that emotional component is very crucial when it comes to customer satisfaction related to a specific product/brand. Similarly, a highly efficient and expert employee of the company contractor even conducted the building task to ensure that the environment after the order was enjoyable and fulfilled. Capital and company manufacturers and dealers are reluctant to ask for active positions to terminate their earnings (Levitt, 1983).

\section{Limitations}

There are many limitations to this study that we conducted, the first being that 
the questionnaire designed, was just focused on physical buying trends and did not bring into consideration the domain of digital marketing and e-commerce as it is one thing that a majority of the population have shifted towards in the recent times. The reason behind developing such a questionnaire is the current trends of people of the target area that is, Karachi and other areas of Pakistan where people are still going out and shopping physically. Moreover, the questionnaire was adapted and improvised from the CEIS (Consumer Emotional Intelligence Scale), which itself contains a lot of questions that test a person by showing pictures, and later on, some questions are scenario-based(Kidwell et al., 2007). Similarly, MSCEIT ${ }^{\mathrm{TM}}$ (Mayer-Salvoy-Carusso-Emotional Intelligence Test) has different phases which are divided over 70 questions and the same goes for TEIQue (Trait Emotional Intelligence Questionnaire).

\section{Recommendations}

According to the findings of the present study, it can be concluded that a consumer's decision-making is primarily related to the understanding of the emotional intelligence of a consumer (Seller to be emotionally intelligent) and the understanding of the rationale of a consumer (Seller to be rational). The reviewed literature presents similar findings. Therefore, it recommends the stakeholders of a similar field to pay attention to both factors including the understanding of the emotional intelligence of a consumer and the understanding of the rationale of a consumer.

\section{Future Scope of Research}

As established earlier, there are no articles that are solely focused on this specific topic. This may be because the organizations are at the moment busy in training their employees to improve the efficiency of the organization and then, later on, use it as a crucial tool to understand the emotional intelligence of the consumers and then start working accordingly. It is a detailed, long and tiring process but it may, in the end, sound fruitful because the whole world has started to go digital, especially after being in midst of a pandemic. The trends are shifting and as a result, the organizations will have to move in with the shifts to keep up. This also opens room for the organizations to create shifts and understand the shifts before they even occur. 


\section{REFERENCES}

Ahmed, Z., Asim, M., \& Pellitteri, J. (2019). Emotional intelligence predicts academic achievement in Pakistani management students. International Journal of Management Education, 286-293.

Ahn, H., Sung, Y., \& Drumwright, M. E. (2015). Consumer emotional intelligence and its effects on responses to transgressions. Springer.

Bhalerao, H., \& Sharma, K. (2018, August). The Impact of Emotional Intelligence on Customer Satisfaction and Repeat Buying Behavior among Young Consumers: An Assessment of the Moderating Role of Dental Health Consciousness. 24(4), 89-108.

HEJASE, H. J., SKAFF, Y., SKAFF, D. E., \& HEJASE, A. J. (2018, September). Effect of Education and Emotional Intelligence on Consumers' Impulsive Buying Behavior. International Review of Management and Business Research, 7(3), 732-757.

Jones, E. (2018). MAKING PRACTICE MORE AFFECTIVE: EMOTIONAL INTELLIGENCE AS A LEGAL META-COMPETENCY. European Journal of Current legal issues, 24(1), 1-18.

Kartol, A., \& Gundogan, S. (2020). THE MEDIATING ROLE OF EMOTIONAL INTELLIGENCE IN THE RELATIONSHIP BETWEEN THE FEAR OF MISSING OUT IN SOCIAL ENVIRONMENTS (FoMO) AND DEPRESSION. European Journal of Education Studies, 1-15.

Kidwell, B., Hardesty, D. M., \& Childers, T. L. (2007). Consumer Emotional Intelligence Scale Measure. Consumer Emotional Intelligence Scale. https://fbfObfb4-17da4e50-8110-

50d425970f0d.filesusr.com/ugd/bc96ae_03cfcb92b2404c21a64d0dd63bfb7d1b.p $d f$

Koc, E., \& Boz, H. (2019). Development of hospitality and tourism employees' emotional intelligence through developing their emotion recognition abilities. JOURNAL OF HOSPITALITY MARKETING \& MANAGEMENT, 1-18.

Lopez-Galan, B., de-Magistris, T., \& Caputo, V. (2017). The impact of emotional intelligence of consumers when purchasing products with nutritional claims. 2017 International Congress, Parma.

Mattingly, V., \& Kraieger, K. (2018). Can emotional intelligence be trained? A metaanalytical investigation. Human Resource Management Review, 140-155.

Mayer, J. D., \& Salvoy, P. (1997). Mayer-Salvoy-Caruso Emotional Intelligence Test. Mayer-Salvoy-Caruso Emotional Intelligence Test.

Mehta, S., Saxena, T., \& Purohit, N. (2020). The New Consumer Behaviour Paradigm amid COVID-19: Permanent or Transient? Journal of Health Management, 291 301.

Misron, A., \& Hee, O. C. (2021, February 11). A Conceptual Analysis of Tech-Savvy Trait, Emotional Intelligence and Customer-Oriented Behaviour among Malaysian Nursing Students. International Journal of Academic Research in Business and Social Sciences, 11(2), 679-694.

Nadeem, H., Akmal, M., Omar, S., \& Mumtaz, A. (2017). IMPACT OF GENDER, EDUCATION, AND AGE ON IMPULSIVE BUYING: MODERATING ROLE OF CONSUMER EMOTIONAL INTELLIGENCE. International Journal of Transformation in Operational \& Marketing Management, 4-17.

Nair, R. (2019). The impact of emotional and demographic factors on impulsive buying behavior of adolescents in Bangalore, India. Indian Journal of Economics and 
Development, 1-10.

O'Connor, P. J., Hill, A., Kaya, M., \& Martin, B. (2019, May 28). The Measurement of Emotional Intelligence: A Critical Review of the Literature and Recommendations for Researchers and Practitioners. Frontiers in Psychology, 10(1116), 1-19.

Ozili, P. K., \& Arun, T. (2020). Spillover of COVID-19: Impact on the global economy. Retrieved March Friday.

Pakistan population. (2020). https://www.worldometers.info/world-population/pakistanpopulation/

Park, H. J., \& Dhandra, T. K. (2016a). Relation between dispositional mindfulness and impulsive buying. Elsevier, 208-212.

Park, H. J., \& Dhandra, T. K. (2016b). Relation between dispositional mindfulness and impulsive buying tendency: Role of trait emotional intelligence. Elsevier, 208-212.

Rajput, N., \& Talan, A. (2017, July-September). Impact of Impulsive Buying Behavior and Opinion Leadership on the Relationship between Emotional Intelligence and Consumer Satisfaction of Smartphone buyers. Global Journal of Enterprise Information System, 9(3), 72-81.

SERGIENKO, E., KHLEVNAYA, E., \& OSIPENKO, E. (2020). Development of an objective methodology for measurement of emotional intelligence. Emotional intelligence and socio-demographics of employees in Russian organizations. ORGANIZATIONAL PSYCHOLOGY, 10(1), 45-61.

Stankevich, A. (2017). Explaining the Consumer Decision-Making Process: Critical Literature Review. Journal of International Business Research and Marketing, 2(6), 7-14.

Vredeveld, A. J. (2018). Emotional intelligence, external emotional connections, and brand attachment. Journal of Product \& Brand Management, 27(5), 545-556.

Zafar, A., Qiu, J., Shahzad, M., Jie, S., Bhuto, T. A., \& Irfan, M. (2020). Impulse buying in social commerce: bundle offer, top reviews, and emotional intelligence. Asia Pacific Journal of Marketing and Logistics.

Zia, M. H., Shafique, S., \& Rajput, A. (2018). The influence of gender-based emotional intelligence on impulsive buying. International Journal of Business Management, 65-75. 